OPEN ACCESS

Edited by:

Lynn Valerie Monrouxe,

The University of Sydney, Australia

Reviewed by:

Julia Choate

Monash University, Australia

Madawa Chandratilake,

University of Kelaniya, Sri Lanka

${ }^{*}$ Correspondence:

Sara E. North

snorth@umn.edu

Specialty section:

This article was submitted to Healthcare Professions Education,

a section of the journal

Frontiers in Medicine

Received: 23 July 2021 Accepted: 17 January 2022

Published: 10 February 2022

Citation:

Webster P and North SE (2022) Health Professions Educational Debt:

Personal, Professional, and

Psychological Impacts 5 Years

Post-graduation

Front. Med. 9:746463.

doi: 10.3389/fmed.2022.746463

\section{Health Professions Educational Debt: Personal, Professional, and Psychological Impacts 5 Years Post-graduation}

\author{
Patrick Webster and Sara E. North* \\ Division of Physical Therapy, University of Minnesota, Minneapolis, MN, United States
}

Introduction: Cost burden in health professions education is rising. To bridge the gap between growing tuition and stagnating wages, student loans are increasingly obtained to cover educational costs. The spiraling after-effects are a source of acute concern, raising alarms across institutions and occupations. There is little dissemination to date of feasible data collection strategies and outcomes beyond 1 year post-graduation. Research is needed in evaluating the impacts of healthcare educational debt on career and personal choices following transition to practice.

Materials and Methods: This study utilized a cross-sectional, mixed methods design. Doctor of Physical Therapy (DPT) Program graduates 5 years following degree completion completed a quantitative online survey, with topics including debt-to-income ratio, educational debt repayment strategies, impact on personal factors, non-education debt, and perceived value of their health professions education. Subsequent phone interviews were conducted by student researchers to gain insights into alumni perceptions of the impacts of educational debt on personal and professional decision-making. Data analysis involved descriptive and correlational quantitative statistics and open and axial coding of interview constructs.

Results: The mixed methods format was successful in obtaining desired depth of response data. Quantitative findings demonstrated primary factors impacted by educational debt as savings, housing, leisure, discretionary spending, and family planning. Qualitative findings revealed impacts on themes of "personal factors" (81\%), "professional factors" (62.5\%), and "psychological factors" (56\%) 5 years after graduation. Most negatively impacted were housing decisions, hours worked, initial job selection, and ability to save for the future, contributing to decreased mental health wellbeing with anxiety, frustration, and guilt. The majority (75\%) of respondents perceived a high degree of value during and following their DPT education, though many expressed discordance between expectations and realities of practice.

Discussion: Findings demonstrate that impacts of health professional educational debt in professional, personal, and psychological factors continue 5 years following degree completion, regardless of debt load. Successful implementation of this pilot methodology indicates potential for use of such extended data collection strategies. 
Further research is needed at the programs, profession, and/or interprofessional level to garner depth of understanding to guide interventions designed to mitigate or prevent these long-term repercussions.

Keywords: education, debt, impact, health professions, physical therapy

\section{INTRODUCTION}

The current generation of health professional program graduates faces a growing problem: the cost of entry-level education. Unlike some countries offering low- or no-cost college tuition, individual cost burden and correlated debt loads in the United States are rising, and the spiraling after-effects are rightly a source of acute concern raising alarms across institutions and occupations (15). Since 1989 , graduate and undergraduate tuition has risen between 100 and 200\%, contrasting with a $<2 \%$ increase in wages, both adjusted for inflation (6). Even smaller salary increases have been seen among healthcare professions during the same period due to changing models of reimbursement (7). To bridge the gap between growing tuition and stagnating wages, student loans are increasingly obtained to cover educational costs (8-11). Student loans now make up the second largest source of consumer debt in the United States with evidence suggesting professional students, including those in health care programs, face particularly high burdens $(12,13)$.

Existing data suggests few health care graduate students can complete their education without accumulating student loans. According to information collected by the College Board $84 \%$ of medical students and $90 \%$ other health science students graduate with debt (7). Average debt loads vary among professions: in US dollars, $\$ 200,000$ for physicians (2019), $\$ 183,014$ for veterinarians (2019), $\$ 40,000-54,999$ for graduate level nurses (2017), $\$ 114,706$ for physician assistants (2017), and between $\$ 83,000-124,000$ for physical therapists (14-17). However, outside of medicine neither total debt loads nor the percentage of graduates accruing debt are systematically tracked restricting understanding of the issue (18-20).

Beyond this foundational data, a small body of literature has explored the influence of debt on career trajectory and personal factors. Higher debt levels have been found to affect the selection of specialties in medicine, pursuit of residencies in pharmacy, and choice of practice areas within physical therapy (19-27). Examining the personal effects of debt on medical students, Rohlfing et al. found that relative to peers at the same institution, greater debt load was associated with delays in having children, buying a home, and marriage, as well as higher levels of callousness (insensitivity) and reduced likelihood of choosing to practice in an underserved location (27). The few sources that have examined these issues outside of medicine demonstrate debt's negative impact $(7,11,18)$. Limited research indicates prioritizing salary over elements of job satisfaction or preferred practice setting may contribute to burnout and decreased professional development and higher debt loads are consistently associated with lower levels of personal wellbeing (24, 27-34). Importantly, most existing research has explored these effects within a narrow timeframe. Information is typically collected immediately after or within 1 year of graduation, restricting the durational understanding of debt's impact (7, $18,20,21,29)$. There is little dissemination to date of feasible data collection strategies and outcomes beyond 1 year postgraduation. Further research is needed in evaluating the impacts of healthcare educational debt on career and personal choices following transition to practice.

To address current gaps in the literature, this study examines the extended effects of educational debt through a mixed methods approach, contributing quantitative data, narrative contextualization, and a sample methodology to the small existing body of evidence. The primary study objective was to examine health professional graduates' perceptions of the personal, professional, and psychological impacts of educational debt 5 years following degree completion. The secondary study objective aimed to evaluate a simple methodological approach for data collection and analysis of graduates perceptions. Recognizing educational debt as a broad problem for all health professions, this study pilots a data collection approach for graduates from one health profession, with the design intended to be applicable for any educational program.

\section{MATERIALS AND METHODS}

This study utilized a cross-sectional, mixed methods design. The sample population included one cohort of 50 Doctor of Physical Therapy (DPT) Program graduates 5 years following DPT degree completion from the author institution, class of 2014, with data collection in fall 2019. IRB approval (\#STUDY00006956) was obtained prior to data collection. Eligible individuals were sent a personalized email template inviting them to participate in a faculty-led student research project. Participants completed a primarily quantitative online survey regarding physical therapist educational debt, debt repayment strategies, impact on personal factors, non-education debt, and perceived value of their health professions education. Those who opted in and consented to survey participation received a $\$ 5$ Amazon e-gift card.

Survey participants were then invited to share their contact information to engage in a 15 -min interview by phone. This duration was selected out of respect for the additional time invested to complete the 10-min online survey. Interview questions were crafted to gain insight into topics of interest that may be poorly captured if included in the online survey, including alumni decision-making in selecting their first position, financial impacts of debt across professional and personal life, experiences with financial-related burnout in work, perceptions of financial literacy education during PT school, and long-term (5-year) perceptions of the value of their DPT education. Structured focused interviews (35) were conducted 
TABLE 1 | Participant demographics.

\begin{tabular}{lc}
\hline Demographics & $\begin{array}{c}\text { Respondents } \\
(\boldsymbol{n}=\mathbf{1 7})\end{array}$ \\
\hline Age (years) & 1 \\
$<30$ & 12 \\
$30-34$ & 1 \\
$35-39$ & 3 \\
$40-44$ & \\
Gender & 12 \\
Female & 5 \\
Male & \\
State of residence & 13 \\
State of author institution & 3 \\
Adjacent state & 1 \\
Non-adjacent state & \\
Population size of residence & 9 \\
$>500,000$ & 3 \\
50,000-500,000 & 5 \\
$<50,000$ & \\
Household income & 1 \\
1 income & 6 \\
2 income, respondent's is higher & 2 \\
2 income, respondent's is lower & \\
\hline
\end{tabular}

by student researchers using a standardized script to promote consistent phrasing of the greeting, question language, follow up question language, and closing remarks. This approach was also selected to mitigate potential bias given that data collection was performed by second year students accruing DPT educational debt. To further address this potential limitation, the faculty researcher led a discussion in bias and reflexivity in advance of interviews to prepare the students to separate their personal reactions from the interview process.

Informed consent was obtained by all participants prior to data collection. Quantitative survey questions were modeled after the physician Graduate Questionnaire (GQ), mirrored existing questions from the program exit survey, and included standardized scales such as the Oldenburg Burnout Inventory (21, 32, 33, 36-38). Topics included debt-to-income ratio, educational debt repayment strategies, educational debt's impact on personal factors, non-education debt, and perceived value of DPT education. Survey responses were submitted to a secure, online data management research platform. The phone interview was developed by study personnel to offer greater narrative depth to the topics covered in the online survey. Interview topics included factors in job choice, financial and personal decisions impacted by educational debt, burnout in clinical practice, and perceived value of their DPT education. Each researcher conducting the interview entered annotated responses directly into the secure online data management research platform noted above.

Quantitative analysis of aggregate online survey question responses included descriptive statistics for participant demographics, salary, and educational debt and correlational
TABLE 2 | Participant salary and total educational debt.

\begin{tabular}{|c|c|}
\hline $\begin{array}{l}\text { Salary and debt } \\
\text { (\$) }\end{array}$ & $\begin{array}{l}\text { Respondents } \\
\qquad(n=17)\end{array}$ \\
\hline \multicolumn{2}{|l|}{ Annual salary (\$) } \\
\hline 60,000-69,999 & 2 \\
\hline 70,000-79,999 & 4 \\
\hline 80,000-89,999 & 8 \\
\hline 90,000-99,999 & 2 \\
\hline $100,000-109,999$ & 0 \\
\hline$>110,000$ & 1 \\
\hline \multicolumn{2}{|c|}{ Total educational debt (\$) } \\
\hline 0 & 3 \\
\hline $0-20,000$ & 1 \\
\hline $20,000-40,000$ & 0 \\
\hline $40,000-60,000$ & 2 \\
\hline $60,000-80,000$ & 1 \\
\hline $80,000-100,000$ & 3 \\
\hline $100,000-120,000$ & 3 \\
\hline $120,000-140,000$ & 1 \\
\hline$>140,000$ & 3 \\
\hline
\end{tabular}

analyses (Spearman Rho, $p<0.05$ ) to explore the relationships between each of (educational debt, monthly debt payment/salary ratio, monthly debt payment) with each of (number of life factors impacted by debt, age, burnout score).

Participant phone interview responses were de-identified prior to analysis. Qualitative analysis began with open coding, the research team (4 graduate DPT students and 1 DPT faculty) individually evaluating all participants' responses to iteratively develop a unique set of codes by which to represent those responses. The research team then established a shared set of codes, with disagreements resolved by consensus. Each researcher revisited participant's responses, assigning the new codes, continuing until the team agreed on the coding selection for each participant response. The next phase of axial coding required the collective research team to analyze the relationships across the initial open coding responses and reassemble the information to develop overarching themes in responses. Disagreements between research team members were discussed and resolved via majority vote. Finally, participant response rates for each code and theme were calculated by tallying the frequencies in aggregate.

\section{RESULTS}

\section{Quantitative}

Of 50 eligible alumni, 17 participants completed the quantitative online survey (34\% response rate). The majority of respondents resided in the state of the author institution and were between 30 and 34 years of age. Refer to Table 1 for participant demographics. The most frequently reported annual salary range was \$80,000-89,000/year. Educational debt levels were more evenly distributed between $\$ 0->\$ 140,000$. Both annual salary and educational debt data are found in Table 2. The personal factors most commonly cited as impacted by educational 
TABLE 3 | Personal factors impacted by total educational debt.

\begin{tabular}{lc}
\hline $\begin{array}{l}\text { Personal factors impacted by total } \\
\text { educational debt }\end{array}$ & Respondents \\
(Choose all that apply) & $(\boldsymbol{n}=\mathbf{1 7})$ \\
\hline Savings & 15 \\
Housing & 14 \\
Leisure & 13 \\
Discretionary spending & 12 \\
Family planning & 11 \\
Transportation & 6 \\
Other loans & 5 \\
Other & 1 \\
\hline
\end{tabular}

TABLE 4 | Correlational comparison between each of (educational debt, monthly debt payment/salary ratio, and monthly debt payment) with each of (number of life factors impacted by debt, age, and burnout score).

\begin{tabular}{|c|c|c|}
\hline Correlational comparison (Spearman's $\rho$ ) & $\rho$ (rho) & $\begin{array}{l}p \text {-value } \\
\text { (CI 95\%) }\end{array}$ \\
\hline \multicolumn{3}{|l|}{ Moderate positive correlations } \\
\hline Higher educational debt vs. younger age & 0.45 & 0.07 \\
\hline $\begin{array}{l}\text { Higher educational debt vs. higher \# of life } \\
\text { factors affected by debt }\end{array}$ & 0.37 & 0.14 \\
\hline \multicolumn{3}{|l|}{ Weak positive correlations } \\
\hline $\begin{array}{l}\text { Higher educational debt vs. higher total } \\
\text { burnout score }\end{array}$ & 0.29 & 0.26 \\
\hline $\begin{array}{l}\text { Higher monthly debt payment/salary ratio vs. } \\
\text { younger age }\end{array}$ & 0.29 & 0.25 \\
\hline \multicolumn{3}{|l|}{ Negligible correlations } \\
\hline Higher monthly debt payment vs. younger age & 0 & 1 \\
\hline $\begin{array}{l}\text { Higher monthly debt payment/salary ratio vs. } \\
\text { higher total burnout score }\end{array}$ & -0.06 & 0.83 \\
\hline \multicolumn{3}{|l|}{ Weak negative correlations } \\
\hline $\begin{array}{l}\text { Higher monthly debt payment/salary ratio vs. } \\
\text { higher \# of life factors affected by debt }\end{array}$ & -0.29 & 0.26 \\
\hline $\begin{array}{l}\text { Higher monthly debt payment vs. higher \# of } \\
\text { life factors affected by debt vs. }\end{array}$ & -0.3 & 0.23 \\
\hline \multicolumn{3}{|l|}{ Moderate negative correlations } \\
\hline $\begin{array}{l}\text { Higher monthly debt payment vs. higher total } \\
\text { burnout score }\end{array}$ & -0.4 & 0.11 \\
\hline
\end{tabular}

Strength of correlation coefficients determined using Dancey and Reidy's interpretation (39).

debt are found in Table 3. The factors cited by more than half of interviewees were savings (88.2\%), housing (82.4\%), leisure $(76.5 \%)$, discretionary spending $(70.6 \%)$, and family planning (64.7\%). Correlational analyses, found in Table 4, demonstrated no statistical significance (Spearman's Rho, $p<$ 0.05) when comparing each of (educational debt, monthly debt payment/salary ratio, monthly debt payment) with each of (number of life factors impacted by debt, age, burnout score).

\section{Qualitative}

Of the 17 participants completing the survey, 16 also engaged in the subsequent qualitative phone interview (32\% response rate).
Though the invitation to participate suggested a 15-min duration, interviews typically extended to $25-30 \mathrm{~min}$ at the discretion of the respondent due to engagement in meaningful conversation. Through open and axial coding, participant responses within the phone interviews regarding the impact of educational debt were categorized into 6 themes: "personal factors" affected by debt, "personal factors" unaffected by debt, "professional factors" affected by debt, "professional factors" unaffected by debt, "psychological factors" affected by debt, and "psychological factors" unaffected by debt.

Personal impact related to life-style factors and spending, not directly related to participants' jobs. Professional impact included any statement directly in reference to participants' past or present job and/or career path. Psychological impact encompassed any participant statements that referenced emotional state, mental health, or behavior. "Other factors" served as an additional categorization to capture remaining concepts not otherwise incorporated.

Qualitative themes and sample participant responses are presented in Table 5. Qualitative results in pictorial form are presented in Figure 1. Note that the number of respondents reporting each factor is represented by the size of the bubbles, with larger bubbles indicating a greater volume of responses. Factors reported as impacted by educational debt are represented in the top half of the figure, while factors unaffected by educational debt are represented in the bottom half of the figure. Findings are color-coded to indicate the associated category of professional, personal, and psychological factors, further described below.

Responses regarding the impact of educational debt on "personal factors" were categorized as affected for $81 \%$ of participants and unaffected for the remaining 19\% of participants. Eight participants cited housing decisions as affected by debt, five cited savings for the future, and three each cited leisure activities and family planning. Despite the high number of respondents citing home buying, most were still able to purchase a home albeit on a delayed timeline or with a smaller mortgage. Several participants drew direct comparisons between student and home loans. A number of respondents reflected, for themselves and other graduates, on the differences in perceived personal burden depending on whether one had a joint income or sole income household. Some also commented on relationships in which both individuals have high student debt, exacerbating the impacts on personal factors further. Sample participant responses regarding impact on personal factors are presented in Row 1 (Table 5).

Responses regarding the impact of educational debt on "professional factors" were categorized as affected for $62.5 \%$ of participants and unaffected for the remaining $37.5 \%$ of participants. For those professionally affected, job choice was dictated primarily by salary, opportunity for loan forgiveness, or access to benefits. Job setting selection within this group was less focused on specialization, and typically included skilled nursing facilities, travel physical therapy, and home health. For those professionally unaffected, job choice was dictated by factors other than money (practice setting, location, and available 
TABLE 5 | Qualitative themes and example responses.

\begin{tabular}{|c|c|c|c|}
\hline Qualitative themes & Affected & Unaffected & Example responses \\
\hline 1. Impact on Personal & $81 \%$ & $19 \%$ & All: Educational debt has affected buying a house, a car, every big purchase. \\
\hline \multirow[t]{5}{*}{ Factors } & & & Housing: My student loan is more than the cost of my first house. \\
\hline & & & Loans: You can get a home loan for 3\% interest, it's crazy that we charge students $7 \%$. \\
\hline & & & $\begin{array}{l}\text { Budgeting: Travel has been put on hold, I'm more conscious on budgeting. I would like to move but } \\
\text { can't save money because of loan payments. Leisure hobbies have been a low priority because it's } \\
\text { important to try to maintain a budget. }\end{array}$ \\
\hline & & & $\begin{array}{l}\text { Family: Having children required costly medical intervention. I had to rely on my family to help financially } \\
\text { because of so much debt. And even though I have good credit, my family had to co-sign when I took out } \\
\text { housing or medical loans due to astronomical debt. }\end{array}$ \\
\hline & & & Saving: I was not able to save for college for my son, I could not contribute as much as I wanted. \\
\hline \multirow[t]{4}{*}{$\begin{array}{l}\text { 2. Impact on Professional } \\
\text { Factors }\end{array}$} & $62.5 \%$ & $37.5 \%$ & $\begin{array}{l}\text { Salary: It's harder for people who go straight from undergrad to DPT because they don't often have a } \\
\text { spouse, kids, house, and haven't lived in the "real world", then realize salary doesn't go as far as you } \\
\text { think, especially with debt burden. You may know the number of the salary you will be earning, but not } \\
\text { what that means in terms of spending. }\end{array}$ \\
\hline & & & $\begin{array}{l}\text { Work Time: I would work part time if I didn't have to worry about paying off loans and the public service } \\
\text { loan forgiveness requirements. }\end{array}$ \\
\hline & & & $\begin{array}{l}\text { Job choice: I had to do the income-based repayment plan, so l'm locked into working for a non-profit for } \\
10 \text { years. Which is fine, I'm ok with it, but there's no other way I could afford to pay off my loans at all. }\end{array}$ \\
\hline & & & $\begin{array}{l}\text { Benefits: I can't reduce to part time because of feeling like I have to make minimum loan payments and } \\
\text { need full-time benefits because I have to care of my family and provide. }\end{array}$ \\
\hline 3. Impact on Psychological & $56 \%$ & $44 \%$ & Guilt: My debt makes me feel really bad about myself - it's a looming aspect, there is always guilt. \\
\hline \multirow[t]{3}{*}{ Factors } & & & Stress: A coworker mentioned she paid off her loans, and it made me feel really bad about myself. \\
\hline & & & Anxiety: My loans are a heavy weight. \\
\hline & & & $\begin{array}{l}\text { Burnout: Burnout is real, especially because you have to work extra hours to make enough for loan } \\
\text { repayments. }\end{array}$ \\
\hline \multirow[t]{5}{*}{ 4. Other Factors } & & & $\begin{array}{l}\text { Love of the PT profession: I think I liked being blissfully ignorant about debt burden because I was and } \\
\text { still am passionate about what I do. }\end{array}$ \\
\hline & & & Love of the PT profession: No one does what we do. \\
\hline & & & $\begin{array}{l}\text { Perceived value of the PT profession: My perception going in was that we were changing scope of } \\
\text { practice with the DPT and would not have to work so directly under physicians... Still a long way to go to } \\
\text { get to the autonomy of direct access DPT care. }\end{array}$ \\
\hline & & & Perceived value of the PT profession: Pay is low for the help we give. \\
\hline & & & $\begin{array}{l}\text { Decision to enter the PT profession: I think if I knew then what I know now about debt, I would have } \\
\text { chosen a different path like PTA, which is really hard for me to say. }\end{array}$ \\
\hline
\end{tabular}

mentorship). Job choice within this group tended toward greater specialization, including pediatrics, neurologic, opportunities within Veterans Affairs (VA) organizations, or specialty gyms. Amount of time worked was directly impacted by educational debt for participants, with some needing to work more hours, while others desired to reduce hours but felt they could not for financial reasons. These additional jobs were cited as a source of increased stress and negative emotional impact. Three participants stated an interest in working part-time, but none were able to reduce their hours due to loan repayment demands and the associated loss of full-time benefits. Sample participant responses regarding impact on professional factors are presented in Row 2 (Table 5).

Responses regarding the impact of educational debt on "psychological factors" were categorized as affected for 56\% of participants and unaffected for the remaining $44 \%$ of participants. Comments frequently referenced anxiety, stress, and dissatisfaction in relation to debt. When asked about the presence or absence of burnout in practice, 12 respondents denied personal burnout but cited observing burnout in other physical therapists, though this was attributed to practice demands rather than educational debt. Those reporting feelings of burnout attributed them to limited flexibility in decision-making on hours worked or job selection. Sample participant responses regarding impact on psychological factors are presented in Row 3 (Table 5).

The "other factors" category included responses offered by participants without prompting, not directly asked through standardized interview questions. These included comments regarding perceived value of the physical therapy profession, love of the profession, and decision to enter the profession. Over half shared a continued love of the physical therapy profession 5 years following graduation, though 19\% stated they may have considered other career options specifically due to the educational debt incurred. In two cases, training as a physical therapist assistant was mentioned as a less costly alternative. Sample participant responses regarding other factors are presented in Row 4 (Table 5). 


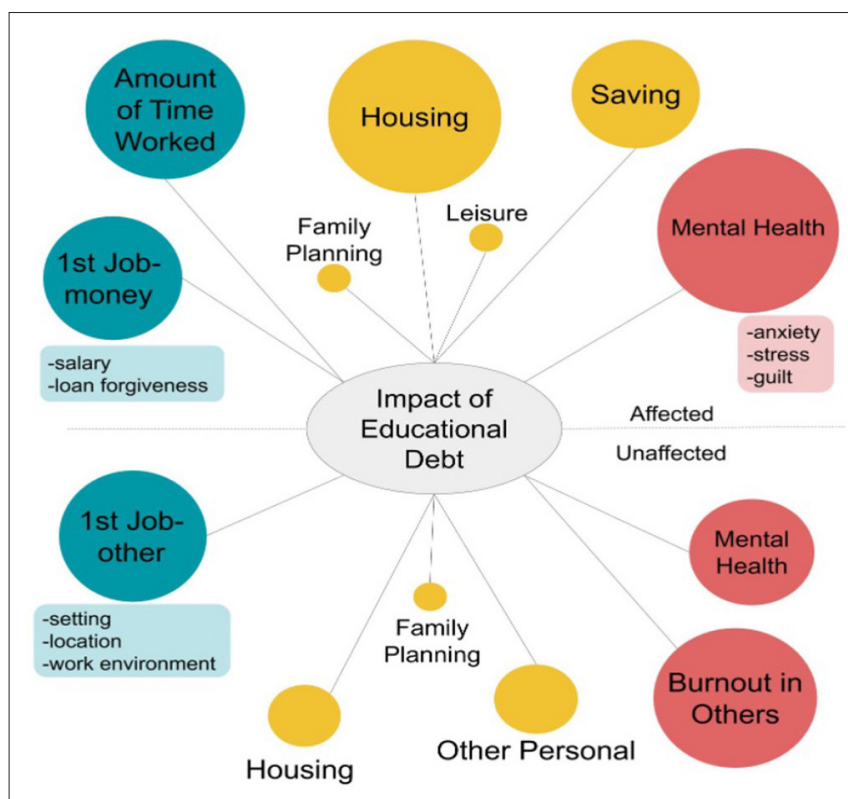

FIGURE 1 | Qualitative themes identified as affected or unaffected by DPT educational debt. The frequency of participants reporting each factor is represented by the size of bubbles, with larger bubbles indicating more responses.

A near universal theme among participants was the desire to have addressed student loan burden sooner. One noted, I wish it was something that we would have talked about earlier so we could start thinking and planning. Nearly $90 \%$ of respondents felt ill-prepared by their academic institutions or lenders to deal with their debt loads, one commenting, I felt like I was blindly taking out loans in school. Many reflected they would have made different borrowing choices if they had more information prior to or during their DPT education, though a number commented by that point loans were already obtained so may have been too late.

Despite incurring educational debt, many respondents reported that the financial investment to earn a DPT degree was worthwhile. The majority (75\%) of respondents perceived a high degree of perceived value during and following their DPT education. Some directly commented on sustained or increased perceived value regarding their DPT education 5 years following degree completion. One specified that this is due in part to the high stability and reasonable salary earned as a physical therapist. Another commented that their confidence in practice is due in part to receiving a high-quality education. Many respondents demonstrated clear pride in the PT profession and in being a PT.

However, unprompted, nearly two thirds of participants stated that they felt physical therapists are undervalued in practice, citing lower than expected pay and a lack of autonomy. Most believed the profession lacked an autonomy of practice commensurate with the DPT education level. One reflected, going into the program, I thought I would have more autonomy. Now I realize the medical field is highly determined by physicians and insurance. Pay was frequently tied to comments about perceived value of the PT profession and benefits offered.

\section{DISCUSSION}

This study adds to the growing body of literature exploring the impacts of health professional educational debt, unique in its data collection 5 years following graduation as opposed to the more common new graduate or 1 year post-graduate perspectives. Findings support and expand understanding of the extent to which educational debt acquired to pursue the DPT degree impacts professional, personal, and psychological factors beyond the first year after degree completion. This line of research has implications for all health professional programs and professional associations in their efforts to both better understand and mitigate negative effects of educational debt.

The lack of correlation found quantitatively between the amount of educational debt (operationalized in three ways: total educational debt, amount of monthly debt payment, and monthly debt payment to salary ratio) and the degree of impact (operationalized as number of life factors impacted by debt and burnout score) indicates that the negative repercussions of incurred educational debt over time are not limited only to those with significantly high debt load. These findings suggest instead that health professions alumni perceive impacts of their educational debt on their lives, regardless of the amount of debt incurred. Interventions from health professions education programs should therefore be tailored for all prospective and/or current students, regardless of amount of educational debt.

Qualitative findings demonstrate that one potential mitigating factor may be to increase financial education provided to students $(1,18,29)$. Questions remain around who is most responsible and what timing is most effective for providing information related to personal financial management and decision-making. Though respondents in this study frequently reported a lack of knowledge and practical skills in managing educational costs as students, opinions varied as to whether responsibility for this education fell to students and their families, undergraduate universities, professional programs, or external financial institutions. Because many students enter their health professions program with prior undergraduate debt and incur more significant debt during their graduate education, it may be most beneficial to provide financial training prior to matriculation $(1,22)$. However, participants in this study frequently cited the desire to learn cost saving strategies during DPT education, echoing findings by Stepp et al. who recommended incorporating financial literacy into DPT curriculum as a useful way to reduce the impacts of educational debt on graduates (20).

Another mitigating factor for health professions programs may be to increase transparency of total degree cost and projected debt to income ratios to better inform potential applicants of their financial commitment. As a positive example, since data collection for this study, the American Physical Therapy Association published a position statement promoting financial transparency and financial literacy for applicants and students (40). Collaborations across multiple health professions educator associations may have even greater capacity to develop interventions and outcomes evaluation processes for the impacts on all health professions students and graduates. 
The mixed methods, cross-sectional design in this study promoted procurement of the desired depth of response data. Quantitative results offered baseline contextual information regarding program graduates' debt and income status, current wellbeing, and perceptions of educational value, while qualitative results provided additional depth regarding a variety of perceived impacts of education debt. Successful implementation of this pilot methodology indicates potential for use of similar extended data collection strategies.

While the scope of this pilot involved a small sample size from one health profession program, the novel data collection approach demonstrates promise for generalizability in exploring the broader, longer-term effects of educational debt by any professional program. The proposed categorization of resultant impacts on personal, psychological, and professional factors provides a consistent framework for qualitative data analysis and reporting to promote comparisons over time, across programs, and across health professions. Multi-institution collection of alumni perspectives at graduation and expanded to five or more years post-graduation will provide insights to programs and to the collective professional organizations regarding the impacts of educational debt beyond solely bank accounts. This data may then serve as a catalyst for actionable steps to better inform, support, and prepare current and prospective students, and to design data-informed efforts to proactively mitigate or prevent the long-term repercussions of educational debt.

In the absence of centralized national data collection systems for allied health profession programs, it is imperative that programs begin to systematically gather information on educational debt and its impact along a shared timeline. Further research is needed at the programs, profession, and/or interprofessional level to generate greater depth of understanding, allowing more comprehensive analysis to

\section{REFERENCES}

1. Commission on Accreditation in Physical Therapy Education. Aggregate Program Data: 2019-2020 Fact Sheet. Available online at: https://www. capteonline.org/globalassets/capte-docs/aggregate-data/2019-2020aggregate-pt-program-data.pdf (accessed May 2020).

2. Dunn S. 2019 Presidential Address. (2019). Available online at: https://www. apta.org/article/2019/06/11/2019-presidential-address (accessed May 2020).

3. Lucca DO, Nadauld T, Shen K. Credit supply and the rise in college tuition: evidence from the expansion in federal student aid programs. Rev Financial Stud. (2019) 32:423-66. doi: 10.1093/rfs/ hhy069

4. Grey G, Hedlund A. Accounting for the rise in college tuition. No. w21967. National Bureau of Economic Research (2016). Available online at: https:// www.nber.org/papers/w21967 (accessed August 2020).

5. Abel JR, Deitz R. Do the benefits of college still outweigh the costs? Curr Issues Econ Finance. (2014) 20:1-12.

6. Baum S, Steele P. The Price of Graduate and Professional School: How Much Students Pay. Access Lex Institute (2017) Available online at: https://www. urban.org/sites/default/files/publication/91016/price_of_grad_professional_ school_2.pdf?mod=article_inline\#:\$ $\mid$ sim\$:text=Average\%20published \%20tuition\%20and\%20fees,over\%20the\%20next\%20five\%20years (accessed August 2020). inform state and national professional initiatives in promoting wellbeing in graduate transition to practice. Building upon this study, educational researchers can collaboratively develop a more comprehensive understanding of the interplay between educational debt and the lives of program graduates. Though dissemination of such efforts are beginning to appear in the literature, far more research is needed to develop approaches to reduce or prevent the long-term repercussions, ultimately enhancing the wellbeing of the next generation of health professionals.

\section{DATA AVAILABILITY STATEMENT}

The datasets presented in this article are not readily available because they remain in protected files. Requests to access the datasets should be directed to Sara North, snorth@umn.edu.

\section{ETHICS STATEMENT}

The studies involving human participants were reviewed and approved by University of Minnesota Institutional Review Board. The patients/participants provided their written informed consent to participate in this study.

\section{AUTHOR CONTRIBUTIONS}

All authors listed have made a substantial, direct, and intellectual contribution to the work and approved it for publication.

\section{ACKNOWLEDGMENTS}

The authors acknowledge the scholarly contributions of the members of the research team: Lydia Dahl, DPT, Mackenzie Dwyer, DPT, and Elizabeth Ramos-Young, DPT.

7. Pabian PS, King KP, Tippett S. Debt in professional doctoral health care disciplines, J Phys Ther Educ. (2018) 32:15968. doi: 10.1097/JTE.0000000000000044

8. Ma J. Trends in Higher Education Series. Available online at: https://research. collegeboard.org/pdf/trends-college-pricing-2019-full-report.pdf. Published November 2019 (accessed May 2020).

9. Bustamante J. Average Cost of College \& Tuition. (2019). Available online at: https://educationdata.org/average-cost-of-college/ (accessed May 2020).

10. Tuition Costs of Colleges and Universities. National Center for Education Statistics. Available online at: https://nces.ed.gov/fastfacts/display.asp?id=76 (accessed May 2020).

11. Quinterno J. The Great Cost Shift: How Higher Education Cuts Undermine the Future Middle Class. Demos. Available online at: http://www.demos.org/ sites/default/files/publications/TheGreatCost Shift_Demos_0.pdf. Published March 2012 (accessed May 2020).

12. Stolba SL. Debt Reaches New Highs in 2019, But Credit Scores Stay Strong (2020). Available online at: https://www.experian.com/blogs/ask-experian/ research/consumer-debt-study/ (accessed May 2020).

13. Brown M, Caldwell S. Young Student Loan Borrowers Retreat From Housing and Auto Markets. New York Federal Reserve (2013). Available online at: https://libertystreeteconomics.newyorkfed.org/2013/04/young-studentloan-borrowers-retreat-from-housing-and-auto-markets.html (accessed May 2020). 
14. AACN Releases 2017 Graduate Nursing Student Debt Report. Available online at: https://www.aacnnursing.org/Policy-Advocacy/View/ArticleId/20715/ AACN-Releases-2017-Graduate-Nursing-Student-Debt-Report (accessed August 2020).

15. 2018 AVMA Annual Report. Available online at: https:/www.avma.org/ sites/default/files/2019-10/AVMA-2018-Annual-Report.pdf （accessed August 2020).

16. The Doctor Is Out. Rising Student Loan Debt and the Decline of the Small Medical Practice. Statement for the Record Submitted by the Association of American Medical Colleges (AAMC) to the House of Representatives Committee on Small Business, 11 June 2019. Available online at: http://www.aamc.org/system/files/c/1/ 498034aamcstatementtothehousesmallbusinesscommitteeregardingmedicaled. pdf (accessed August 2020).

17. National Commission on Certification of Physician Assistants, Inc. 2017 Statistical Profile of Recently Certified Physician Assistants: An Annual Report of the National Commission on Certification of Physician Assistants. (2018). Available online at: http://www.nccpa.net/research (accessed August 2020).

18. Thompson K, Coon J, Handford, L. Financing physical therapy doctoral education: methods used by entry-level students and the financial impact after graduation. J Allied Health. (2011) 40:169-73.

19. American Physical Therapy Association (APTA). Workforce Task Force Report. Available online at: https://www.apta.org/your-career/careers-inphysical-therapy/workforce-data/apta-physical-therapy-workforce-analysis (accessed September 2018).

20. Stepp C, Workman C, Kuperstein J. Doctor of physical therapy initial job characteristics and the impact of student debt. Phys Ther J Policy Adm Leadership. (2019) 19:13-22.

21. Shields RK, Dudley-Javoroski SD. Physiotherapy education is a good financial investment, up to a certain level of student debt: an inter-professional economic analysis. J Physio. (2018) 64:183-91. doi: 10.1016/j.jphys.2018.05.009

22. Ambler SB. The debt burden of entry-level physical therapists. Phys Ther. (2020) 100:591-9. doi: 10.1093/ptj/pzz179

23. Youngclaus J. An exploration of the recent decline in the percentage of U.S. medical school graduates with education debt. AAMC Anal Brief. (2018) 18:1-3.

24. Greysen RS, Chen C, Mullan F. A history of medical student debt: observations and implications for the future of medical education. Acad Med. (2011) 86:840-5. doi: 10.1097/ACM.0b013e31821daf03

25. Phillips, RL, Dodoo, MS, Petterson S. Specialty and Geographic Distribution of the Physician Workforce: What Influences Medical Student and Resident Choices? Robert Graham Center. Available online at: http://www. grahamcenter.org/online/etc/medialib/graham/documents/publications/ mongraphs-books/2009/rgcmo-specialty-geographic (accessed May 2020).

26. Rosenblatt RA, Andrilla CH. The impact of U.S. medical students' debt on their choice of primary care careers: an analysis of data from the 2002 medical school graduation questionnaire. Acad Med. (2005) 80:8159. doi: 10.1097/00001888-200509000-00006

27. Rohlfing J, Navarro R, Maniya OZ, Hughes BD, Rogalsky DK. Medical student debt and major life choices other than specialty. Med Educ Online. (2014) 19:25603. doi: 10.3402/meo.v19.25603

28. Koria K. Financial Literacy and the New DPT Grad. PT in Motion. (2017). Available online at: http://www.apta.org/PTinMotion/2017/2/Feature/ FinancialLiteracy/ (accessed September 2018).
29. Jette DU. Physical therapist student loan debt. Phys Ther. (2016) 96:16858. doi: $10.2522 /$ ptj.20160307

30. Riles E. Beating Burnout. PT in Motion. Available online at: https://www.apta. org/apta-magazine/2019/02/01/beating-burnout (accessed May 2019).

31. Cooke R, Barkham M, Audin K, Bradley M, Davy J. Student debt and its relation to student mental health. J Further Higher Educ. (2004) 28:5366. doi: $10.1080 / 0309877032000161814$

32. 2019 AAMC Medical School Graduation Questionnaire. Available online at: https://www.aamc.org/system/files/2019-08/2019gqsurvey.pdf (accessed August 2020).

33. Demerouti, E. The Oldenburg Burnout Inventory: a good alternative to measure burnout and engagement. In: Halbesleben JRB, editor. Handbook of Stress and Burnout in Health Care. Hauppauge, NY: Nova Science Publishers (2008).

34. Krupat E, Camargo CA, Strewler GJ, Espinola JA, Fleenor TJ, Dienstag JL. Factors associated with physicians choice of a career in research: a retrospective report 15 years after medical school graduation. $A d v$ Health Sci Educ Theory Pract. (2017) 22:5-15. doi: 10.1007/s10459-016-9 678-5

35. Ary D, Jacobs LC, Sorensen C. Introduction to Research in Education. 8th ed. Belmont, CA: Wadsworth Cengage Learning (2010).

36. Dahlin $\mathrm{M}$, Joneborg N, Runeson, B. Performance-based selfesteem and burnout in a cross-sectional study of medical students. Med Teacher. (2008) 29:43-8. doi: 10.1080/014215906011 75309

37. Demerouti E, Bakker AB, Nachreiner F, Schaufeli WB. A model of burnout and life satisfaction amongst nurses. J Adv Nurs. (2000) 32:45464. doi: 10.1046/j.1365-2648.2000.01496.x

38. Halbesleben JRB, Demerouti E. The construct validity of an alternative measure of burnout: investigating the English translation of the Oldenburg Burnout Inventory. Work Stress. (2005) 19:208-20. doi: 10.1080/02678370500340728

39. Akoglu A. User's guide to correlation coefficients. Turk J Emerg Med. (2018) 18:91-3. doi: 10.1016/j.tjem.2018.08.001

40. American Physical Therapy Association. Financial Transparency of Physical Therapy Education Programs (HOD P06-20-40-32). (2020). Alexandria, VA: American Physical Therapy Association.

Conflict of Interest: The authors declare that the research was conducted in the absence of any commercial or financial relationships that could be construed as a potential conflict of interest.

Publisher's Note: All claims expressed in this article are solely those of the authors and do not necessarily represent those of their affiliated organizations, or those of the publisher, the editors and the reviewers. Any product that may be evaluated in this article, or claim that may be made by its manufacturer, is not guaranteed or endorsed by the publisher.

Copyright (c) 2022 Webster and North. This is an open-access article distributed under the terms of the Creative Commons Attribution License (CC BY). The use, distribution or reproduction in other forums is permitted, provided the original author(s) and the copyright owner(s) are credited and that the original publication in this journal is cited, in accordance with accepted academic practice. No use, distribution or reproduction is permitted which does not comply with these terms. 